\title{
Correction to: The 3.5-year survival rates of primary molars treated according to three treatment protocols: a controlled clinical trial
}

\author{
Maite Mijan ${ }^{1,2}$ • Rodrigo Guedes de Amorim ${ }^{1}$ - Soraya Coelho Leal ${ }^{2}$ Jan Mulder ${ }^{1}$. \\ Luciana Oliveira $^{3} \cdot$ Nico H. J. Creugers ${ }^{4}$ • Jo E. Frencken ${ }^{1}$
}

Published online: 3 October 2017

(C) Springer-Verlag GmbH Germany 2017

\section{Correction to: Clin Oral Invest (2014) 18:1061-1069 https://doi.org/10.1007/s00784-013-1077-1}

Mw. M. Mijan will defend her PhD thesis on $15^{\text {th }}$ September 2017. Whilst reviewing her work in preparation to the event, we discovered a few irregularities that prompted a recheck of the database and ditto analyses. These activities have lead to a few textual changes in the publication. On behalf of the authors I apologise for these omissions.

Abstract

Page 1061, column 2, line 6: 88.6 changes into 89.0

Results

Figure 1:

UCT group by 3 years, Nteeth changes from 75 into 130

UCT group by 3.5 years, Nteeth changes from 43 into 76

Table 2:

UCT group by 3 years, Nteeth changes from 75 into 130; 88.6 changes into 89.0

UCT group by 3.5 years, Nteeth changes from 43 into 76; 88.6 changes into 89.0

Jo E. Frencken

j.frencken@dent.umcn.nl

1 Department of Global Oral Health, College of Dental Sciences, Radboud University Nijmegen Medical Centre, P.O. Box 9101, 6500 HB Nijmegen, The Netherlands

2 Department of Pediatric Dentistry, School of Health Sciences, University of Brasília, Brasília, Brazil

3 Department of Pediatric Dentistry, São Leopoldo Mandic School of Dentistry, Campinas, Brazil

4 Department of Oral Rehabilitation, College of Dental Sciences, Radboud University Nijmegen Medical Centre, 6500

HB Nijmegen, The Netherlands
Table 3

UCT group by 3 years, Nteeth changes from 38 into 93

UCT group by 3.5 years, Nteeth changes from 22 into 54

Table 4. The number for fistula in the ART group is 11 not

1. This is a typing error.

No change in the conclusion. 